


\section{O Estatuto da intencionalidade na obra A Iranscendência do Ego, de Jean-Paul Sartre}

Fabrício Rodrigues Pizelli

Universidade Estadual Paulista "Júlio de Mesquita Filho"

RESUMO: O objetivo deste artigo é analisar o estatuto da Intencionalidade empregada por Jean-Paul Sartre para demonstrar as teses defendidas em A Transcendência do Ego. Para isso, polemiza-se com algumas aproximações e diferenças do conceito de Intencionalidade utilizado por Husserl e Sartre, e ressalta-se que a grande discrepância entre estes autores consiste na admissão do "Eu" puro como estrutura imanente à consciência, pois o fluxo da consciência intencional husserliana parte de um "Eu" puro fortemente defendido em Ideias I. Contudo, Sartre radicaliza a Intencionalidade husserliana, ao passo que o "Eu" não será admitido na consciência, ele estará no mundo como um objeto transcendente. Portanto, conclui-se o artigo com a tentativa de esclarecer a necessidade da noção de Intencionalidade como sustentáculo da tese do Ego transcendente e etapa para as três consequências conclusivas de A Transcendência do Ego, a saber: a liberação do campo transcendental; uma tentativa de superar o solipsismo e uma possível refutação do idealismo.

PALAVRAS-CHAVE: intencionalidade; solipsismo; transcendência; ego; Sartre. 


\section{CONSIDERAÇÕES INICIAIS}

A noção de Intencionalidade, que perpassa a obra A Transcendência do Ego, assume uma grande importância para a demonstração da tese sartriana de que "o Ego não está nem formalmente nem materialmente na consciência: ele está fora, no mundo; é um ser do mundo, como o Ego do outro" (SARTRE, 1966, p. 13, grifo do autor, tradução nossa). Dessa feita, no ano acadêmico de 1933-1934, em que Sartre substituiu Aron em uma bolsa de estudos do Instituto Francês de Berlim, para estudar fenomenologia (COHEN-SOLAL, 1986), além de escrever A Transcendência do Ego, escreveu um curto ensaio sobre Husserl, o qual intitula-se: Uma ideia fundamental da fenomenologia de Husserl: a Intencionalidade². Ambos os textos tiveram suas redações iniciadas no mencionado ano de estágio de Sartre, de maneira que se pode estabelecer forte relação e indicar proximidade entre eles; porém, embora haja possíveis discrepâncias teóricas entre os dois textos, um ponto de intersecção sobre o estatuto da Intencionalidade os conecta: em ambos os textos de Sartre há clara rejeição da existência de conteúdos imanentes à

1. "l'Ego n'est ni formellement ni matériellement dans la conscience : il est dehors, dans le monde: c'est un être du monde, comme l'Ego d'autrui.".

2. A partir de agora, referir-nos-emos ao breve ensaio sobre Husserl como "A Intencionalidade". 
consciência. Desse modo, o cerne conceitual que faz Sartre tratar Husserl de uma maneira mais elogiosa em A Intencionalidade e de um modo mais crítico em A Transcendência do Ego ainda se mantém.

Com efeito, pode-se notar nos escritos de Berlim a forte adesão de Sartre às teorias husserlianas, de modo que a interpretação de Husserl da Intencionalidade como "ser consciência de algo" (HUSSERL, 2006, p. 190, grifo do autor) será muito utilizada por Sartre ao decorrer de sua filosofia. De acordo com Cohen-Solal, de 1933 até 1939 Sartre só se interessou por Husserl, pois "descobria na fenomenologia husserliana uma tentativa intelectual em que cada etapa, cada tema, cada subterfúgio, tem afinidade com a sua" (COHEN-SOLAL, 1986, p. 137-138). Posteriormente, em 1940, em seus diários de guerra, Sartre afirma que “era 'husserliano' e assim ficaria por muito tempo" (SARTRE, 1983, p. 225), de modo que demorou quatro anos para esgotar Husserl em seus estudos (SARTRE, 1983, p. 226).

Todos esses relatos demarcam a importância de Husserl na construção das teorias do jovem Sartre, sobretudo na noção de Intencionalidade, objeto deste trabalho, pois ela irá permitir "tratar a consciência e o seu objeto como duas entidades distintas, a qual uma se explode em direção à outra, a fim de garantir sua relação" (COOREBYTER, 2000, p. 31). Desse modo, dado o fato de que a Intencionalidade é o que permite a consciência se relacionar com o objeto psíquico, a discussão da consciência intencional também se coloca no terreno do problema do solipsismo, o qual só começa a ser tratado pela fenomenologia de Sartre após a liberação do campo transcendental, tornando-o impessoal. Com efeito, torna-se possível que Sartre lance as bases de uma possível refutação ao idealismo no final d'A Transcendência do Ego. 


\section{O "MITO DA INTERIORIDADE"}

Simone de Beauvoir relata, em A força da idade, que algumas aspirações de Sartre na época já forneciam indícios sobre o porquê de estabelecer críticas ao idealismo e ao realismo. Ocorre que Sartre desejava abolir a psicologia analítica e "empoeirada" que ensinavam na Sorbonne, estabelecendo "uma compreensão concreta, logo sintética, dos indivíduos" (BEAUVOIR, 2018, p. 40-41, grifo do autor). Dessa maneira, pode-se afirmar que sempre esteve latente em Sartre a aspiração de oferecer uma alternativa ao idealismo e ao realismo tradicionais, que só se tornou possível graças à noção de Intencionalidade, fornecida pela fenomenologia, a qual permite pôr um fim no mito da "vida interior", fortemente presente nos teóricos idealistas franceses, em especial, Bergson e Brunschvicg. A noção de intencionalidade apresentada por Husserl permite a expulsão de todos os conteúdos imanentes à consciência, visando a apreender os objetos fora do sujeito, isto é, no mundo. Sartre interpreta a noção husserliana de Intencionalidade como um movimento em direção ao mundo e menciona a definição husserliana: "Husserl exprime nesta famosa frase: 'Toda consciência é consciência de alguma coisa'. Não é necessário mais nada para colocar um fim na filosofia confortável e na imanência”" (SARTRE, 1947, p. 31). Desse modo, podemos ressaltar a importância da noção de Intencionalidade para Sartre, além do fato de que essa influência husserliana em seu pensamento estará muito presente nas demais obras de juventude ${ }^{4}$, até mesmo, em O Ser e o Nada.

De acordo com Mészáros (2012), Sartre, em suas obras de juventude, não se satisfaz em permanecer dentro da esfera subjetiva, tal como os ide-

3. "Husserl exprime dans cette fameuse phrase: 'Toute conscience est conscience de quelque chose. Il n'en faut pas plus pour mettre un terme à la philosophie douillette et l'immanence (...)”.

4. Principalmente no capítulo IV do ensaio crítico A imaginação (1973), e perpassando todo o ensaio científico O imaginário (1996). 
alistas que defendiam a existência de uma vida interior. Dessa maneira, Sartre, ao nos apresentar uma nova concepção sobre o Ego, reivindica que sua proposta é a única refutação possível do solipsismo (SARTRE, 1966). Além disso, pode-se afirmar que Sartre visa "solapar o que chama de "materialismo metafísico', abrindo o parêntese fenomenológico dentro do espírito de um 'realismo's filosófico" (MÉSZÁROS, 2012, p. 101). Com efeito, um dos empreendimentos de Sartre é "captar os 'existentes' em sua facticidade, em oposição às diversas espécies de pressupostos ou prejulgamentos metafísicos" (MÉSZÁROS, 2012, p. 101), tais como os de Kant e Husserl.

Sartre, antes de elaborar seus argumentos positivos em A Transcendência do Ego, critica algumas teorias idealistas e realistas influentes na época. Entre os idealistas, além de Kant e Husserl, temos o neokantismo de Brunschvicg e Lachelier, o empiriocriticismo de Mach e o intelectualismo de Brochard (SARTRE, 1966), e dentre os realistas, temos os moralistas do Amor-próprio, cujo maior expoente foi La Rochefoucauld. Dessa feita, pode-se afirmar que essas teorias mantêm alguma relação com o mito da "vida interior". Em um primeiro momento, em A Intencionalidade, Sartre aspira combater aquilo que ele denomina de "filosofia alimentar" (SARTRE, 1947, p. 30). De acordo com Sartre, essa filosofia estabeleceria uma relação entre conteúdos empíricos e consciência, de maneira que os objetos do mundo seriam assimilados - metabolizados, por assim dizer - pela consciência, constituindo seu conteúdo. É justamente para se contrapor a esse tipo de pensamento que Sartre se aproxima da fenomenologia.

Simone de Beauvoir (2018, p. 116) relata, em A força da idade, que Sartre, ao ser apresentado à fenomenologia de Husserl por Aron, nela viu a

5. É importante salientar que o termo "realismo", utilizado por Mészáros para caracterizar a obra de Sartre, não foi empregado no mesmo sentido do realismo clássico, que deduz a consciência da matéria. Dessa maneira, deve-se entender o realismo, aludido por Mészáros, como uma relação entre os dados originários (consciência e mundo) e não em seu sentido utilizado na tradição filosófica. 
possibilidade de "ultrapassar a oposição do idealismo e do realismo", uma vez que se pode afirmar a soberania da consciência e do mundo ao mesmo tempo. Posto isso, uma das grandes inovações da fenomenologia foi a afirmação do "a priori universal da correlação", estabelecido por meio da noção de Intencionalidade. Deste modo, por meio da consciência intencional, os objetos abandonarão o seu estatuto de "conteúdos da consciência" e serão percebidos no mundo, onde realmente estão. A respeito disso, Sartre (1947, p. 30) já afirmava em A Intencionalidade:

Você vê esta árvore aqui - seja. Mas a vê no mesmo lugar em que está: à beira da estrada, em meio à poeira, só e curvada sob o calor, a vinte léguas da costa mediterrânea. Ela não saberia entrar em sua consciência, pois não é da mesma natureza que ela. ${ }^{6}$

Deste modo, considerando a leitura de Sartre, a Intencionalidade pode ser caracterizada como um "explodir em direção a" (SARTRE, 1947, p. 30), possibilitando que todas as estruturas das teorias clássicas da tradição sejam expulsas para fora da consciência. Por meio da noção de Intencionalidade, os objetos passam a ser transcendentes. Outrossim, com os conteúdos expulsos da consciência, o "Eu” também não poderá ser assimilado na consciência, pois "Já não deverá haver mais representação como imagem ou signo da coisa espaçotemporal. A representação, tal como o Eu, implica a 'vida interior' de que fala Brunschvicg, e Sartre sempre desejou expurgar do campo da imanência" (MOUTINHO, 1995, p. 24).

Com efeito, devido à recepção da fenomenologia de Husserl, Sartre pode estabelecer uma oposição ao idealismo que prega, de alguma maneira uma espécie de introspecção. A respeito disso, afirma Coorebyter:

6. "Vous voyez cet arbre-ci, soit. Mais vous le voyez à l'endroit même où il est: au bord de la route, au milieu de la poussière, seul et tordu sous la chaleur, à vingt lieues de la côte méditerranéenne. Il ne saurait entrer dans votre conscience, car il n'est pas de même nature qu'elle." 
"Sartre nunca defenderá a introspecção, seu interesse pela psicologia vem acompanhado por um ódio feroz pelas dobras da interioridade”? (COOREBYTER, 2000, p. 37). Dessa feita, como investigaremos com mais profundidade em A Transcendência do Ego, devido ao fato de que os extremos do idealismo podem cair no problema do solipsismo, uma vez que concebem as estruturas a priori como imanentes à consciência e, de certo modo, estabelecem uma validade para a existência dos objetos exteriores. Contudo, Sartre lida de maneira diferente com a teoria de Husserl em A Transcendência do Ego, pois, devido ao avanço dos seus estudos fenomenológicos, ele passa a identificar certo idealismo em Husserl, o qual será fortemente criticado em seus escritos da década de 1930 e na ontologia madura de $O$ Ser e o Nada, em 1943. Com efeito, afirma-se que a gênese de uma crítica sistemática e rigorosa à fenomenologia husserliana inicia-se em A Transcendência do Ego, pois, em um primeiro momento, tal crítica consistirá na recusa da noção de "Eu” puro e da síntese das representações por meio de um construto transcendental, uma vez que Husserl, em Ideias I, "ressuscita o Eu transcendental ausente nas Investigações. Isto soará para Sartre como uma infidelidade ao conceito de consciência intencional" (MOUTINHO, 1995, p. 27).

\section{DIVERGÊNCIAS COM HUSSERL}

Sartre ataca a falsa necessidade de estabelecer um "Eu" cuja função é a de operar as sínteses dos vividos, de modo que "tratar-se-á apenas de repor o verdadeiro conceito de consciência adulterado com o ressurgimento do Eu transcendental" (MOUTINHO, 1995, p. 27). Sobre isso, Sartre declara: "Acredita-se, ordinariamente, que a existência de um Eu transcendental

7. "Sartre ne prônera jamais l'introspection, son intérêt pour la psychologie s'accompagnant d'une haine farouche pour les replis de l'intériorité". 
se justifica pela necessidade de unidade e de individualidade da consciência”s(SARTRE, 1966, p. 20). Com efeito, podemos dirigir, sugestivamente, a crítica sartriana da crença ordinária nas afirmações sobre o "Eu", tal como Husserl estabelece em Ideais I.

Em Ideias I, publicada por Husserl em 1913, demarca-se a restauração do "Eu” puro presente na consciência. Com efeito, a noção de Intencionalidade passa a se relacionar com um "Eu” puro, de maneira que o objeto apreendido pela consciência intencional é "fruto de uma síntese desenvolvida através do tempo, graças a uma efetivação (Leistung) intencional do eu” (FRAGATA, 1959, p. 150). Dessa feita, ao levarmos em conta o processo temporal na síntese do objeto, é possível afirmar que, por meio do tempo, a constituição do objeto detém um caráter "genético ou dinâmico" (FRAGATA, 1959, p. 152), de maneira que se pode estabelecer alguns paralelos com a constituição kantiana, pois "a síntese aperceptiva, efectuada pela aplicação da categoria ao dado sensível, se desenvolve também através dum esquema temporal" (FRAGATA, 1959, p. 152). Ademais, Husserl (2006, p. 132, grifo do autor) indica sua aproximação com Kant no $§ 57$ de Ideias I:

\begin{abstract}
Num sentido particular, ele [o Eu puro] esgota sua vida em cada cogito atual, mas também os vividos de fundo lhe concernem, assim como ele a eles; enquanto pertencentes a um único, ao meu fluxo de vividos, todos eles têm de poder ser convertidos ou incluídos de maneira imanente em cogitationes atuais; na linguagem kantiana: "O 'eu penso' tem de poder acompanhar todas as minhas representações".
\end{abstract}

O § 57 tem muita importância na retomada do "Eu" na teoria de Husserl, pois nele busca-se deixar clara a impossibilidade de o "Eu" puro ser

8. "On croit ordinairement que l'existence dun Je transcendantal se justifie par le besoin dunité et dindividualité de la conscience". 
colocado para fora do círculo de análise fenomenológica. Contudo, Husserl admite que, no processo de redução, não se encontra o "Eu" puro em nenhuma parte do fluxo da consciência. Porém, este mesmo "Eu” permanece ligado de maneira necessária à consciência. Sobre isso, atesta Husserl (2006, p. 132, grifo do autor) : "O eu puro, em contrapartida, parece ser algo necessário por princípio (...) ele não pode, em sentido algum, ser tomado por parte ou momento real dos próprios vividos”.

Em outras palavras, as condutas epistêmicas em Husserl, como "se direcionar a algo", "se ocupar com algo", "visar algo", podem ser representadas com um raio intencional com ponto de partida no Eu puro (HUSSERL, 2006, p. 182-183). Ou seja, o Husserl da fenomenologia transcendental de Ideais I estabelece um vínculo formal entre o "Eu" e a Intencionalidade, o qual é rejeitado por Sartre em A Transcendência do Ego, pois tal posição teórica implica um evidente idealismo. Sartre ostenta reservas ao subjetivismo husserliano, "ele ignora essa tendência da fenomenologia para melhor desenvolver uma visão purificada da intencionalidade que serve de antídoto ao subjetivismo"10 (COOREBYTER, 2000, p. 58).

Sartre, ao se questionar sobre a coerência de um "Eu" transcendental, em relação à definição da consciência anteriormente dada por Husserl, refere-se, na verdade, à síntese de três conceitos de consciência postulados por Husserl, os quais são diferenciados e ressaltados em relação aos pos-

9. Os tradutores Pedro M. S. Alves e Artur Morão pontuam em seus trabalhos que, em alemão, há uma distinção entre Real e Reell, porém, em português, essas palavras apenas podem ser traduzidas como real, o que prejudica o sentido da frase, de maneira que, em cada ocorrência, ambos os tradutores marcam os casos de Real e Reell, na medida em que aparecem. Artur Morão explica a distinção: "Real significa em Husserl, real no sentido de mundano, pertencente à realidade natural", enquanto que quer dizer real, "mas em relação apenas aos componentes do vivido, isto é, aquilo que forma parte da consciência e se encontra no tempo fenomenológico" (HUSSERL, 2000, p. 10). Porém, o tradutor brasileiro de Ideais I não pontuou esse detalhe no decorrer de toda a sua tradução. Dessa maneira, ao se conferir, no original, o respectivo termo "real", da presente citação, detém o sentido de Reell (HUSSERL, 1950).

10. "Il ignore cette tendance de la phénoménologie pour mieux développer une vision épurée de l'intentionnalité qui sert d'antidote au subjectivisme". 
síveis equívocos de terminologia. São eles: (i) "Consciência como a consciência fenomenológica real [Reell] conjunta do eu espiritual. (Consciência = o eu fenomenológico, enquanto 'feixe' ou entrelaçamento das vivências psíquicas)" (HUSSERL, 2015, p. 295; grifo do autor, A)"1; (ii) "Consciência como o interno dar-se conta das vivências psíquicas próprias” (HUSSERL, 2015, p. 295, A); (iii) "Consciência como designação global para todo e qualquer tipo de 'atos psíquicos' ou 'vivências intencionais'” (HUSSERL, 2015, p. 295, A). Em síntese, na primeira edição do segundo volume de Investigações Lógicas, em 1901, Husserl dispensa a tese do "Eu" transcendental, porém, faz algumas correções e notas na edição de 1913.

Por conseguinte, o "Eu”, em Husserl, como o "Ego", em Sartre, detêm uma característica em comum: ambos são objetos como os demais objetos. A respeito disso, afirma Husserl: "O eu, no sentido do discurso comum, é um objeto empírico, o eu próprio o é assim tal como o eu alheio, e qualquer eu o é tal como qualquer coisa física, como uma casa ou uma árvore etc.” (HUSSERL, 2015, p. 301, A). Ademais, Husserl indica nesse texto a possibilidade de operar uma síntese da multiplicidade das vivências sem um "Eu" puro, de modo a constituir uma "totalidade unitária de conteúdos que não é outra coisa senão o próprio fenomenologicamente reduzido" (HUSSERL, 2015, p. 302, A). Deste modo, salienta-se que no $\$ 57$ de Ideias I Husserl torna impossível o "Eu” passível de redução, uma vez que o mesmo deve acompanhar todas as representações. Posto isso, Husserl chama atenção, numa nota da segunda edição das Investigações Lógicas: "O autor não aprova mais a oposição, expressa nesse parágrafo [§ 4, 5a Investigação], à doutrina do eu 'puro', como é evidente a partir das suas Ideen" (HUSSERL, 
2015, p. 302, B). Adiante, em um trecho omitido do $\S 4$ da $5^{\text {a }}$ Investigação da segunda edição, Husserl reafirma a possibilidade de o "Eu” ser reduzido e que, mesmo estando fora de circuito, ele possui sua unidade. Sobre isso, Husserl (2015, p. 302, A) declara:

(...) é seguro que o eu fenomenológico reduzido, por conseguinte, o eu segundo a sua consistência em vivências que continuadamente se desenvolvem de momento para momento, é em si próprio portador da sua unidade, possa ele valer ou não, do ponto de vista causal, como uma coisa.

Sobre a unidade das vivências sem um "Eu" puro, é interessante notar que Husserl, durante as Investigações Lógicas, não realiza o mesmo tipo de aproximação com o Eu Penso kantiano, como já mostrado em Ideias I.

Husserl declara que não considerou, até o § 8 das Investigações Lógicas ( $5^{\mathrm{a}}$ investigação), que o eu puro kantiano deve fornecer um ponto de referência unitário à consciência (HUSSERL, 2015, A), de modo que Husserl faz uma confissão na primeira edição: "Devo agora confessar que não consigo encontrar, pura e simplesmente, esse eu primitivo, enquanto centro de referência necessário” (HUSSERL, 2015, p. 310). Porém, em nota, na segunda edição, afirma: "Entretanto, aprendi a encontrá-lo, ou aprendi, na captação pura do dado, a não me deixar transtornar por temores diante dos abastardamentos da metafísica do eu” (HUSSERL, 2015, p. 310). Dessa maneira, a relação de percepção e unidade, primeiramente concebida por Husserl, torna o "Eu" "percebido como qualquer coisa externa" (HUSSERL, 2015, p. 312, A). Em suma, a síntese se dá na própria presença do sujeito com o objeto, sem nenhuma mediação transcendental. Ademais, em um adendo à segunda edição, Husserl observa: "Seja expressamente sublinhado que a minha tomada de posição, aqui realizada (e que já não aprovo, 
como já o disse), a respeito da questão do eu puro permanece irrelevante para as investigações deste volume" (HUSSERL, 2015, p. 312, grifo do autor, $B)$.

Portanto, ressaltada a irrelevância de um "Eu" puro com ponto de unidade dos vividos pela própria fenomenologia de Husserl, Sartre (1966, p. 21) conclui que "é certo que a fenomenologia não necessita recorrer a esse Eu unificador e individualizante" ${ }^{12}$, de maneira que a consciência será definida pela intencionalidade, a qual se transcende a si mesma e se unifica "escapando-se". Adiante, Sartre se baseia em um escrito não reconhecido por Husserl como parte fundamental de sua obra, a saber, Lições para uma fenomenologia da consciência interna do tempo' ${ }^{13}$.

O texto de Lições, de Husserl, recuperado por Sartre, contém algumas peculiaridades que nos permitem compreender o porquê de Sartre utilizá-lo para demonstrar a inutilidade do "Eu” presente na consciência. Em primeiro lugar, o texto de Lições já estava pronto em 1910; porém, só foi publicado em 1928 (HUSSERL, 1994, p. 10). De acordo com a introdução de Pedro M. S. Alves, as Lições foram elaboradas em um período de transição da psicologia descritiva (Investigações Lógicas, de 1901) para a fenomenologia transcendental (Ideais I, de 1913), de maneira que: "Isto significa que delas [das Lições] estão ainda ausentes as peças essenciais da etapa transcendental da fenomenologia: a teoria da redução, a análise correlativa, os conceitos de noese e de noema e, por fim, uma verdadeira teoria da constituição" (HUSSERL, 1994, p. 13). Contudo, a publicação de Lições, elaborada por Edith Stein e editadas por Heidegger, teve o consentimento de Husserl, pois, mesmo ele alterando suas teses em 1913, ainda considerava Lições como uma obra sua (HUSSERL, 1994).

12. "est certain que la phénoménologie n'a pas besoin de recourir à ce Je unificateur et individualisant". 13. Referir-nos-emos a este texto, doravante, apenas como Lições. 
Posto isso, Husserl concebe o processo de síntese como uma articulação das intencionalidades, de maneira a garantir a validade de uma consciência passada. A articulação das intencionalidades, no intuito de constituir uma síntese concreta, dá-se por meio de uma "Intencionalidade transversal" e por uma "Intencionalidade longitudinal" (HUSSERL, 1994, p. 107). A Intencionalidade transversal é responsável por uma protossensação da apreensão - Husserl (1994, p. 105-106) a denomina de "recordação primária" -; e a Intencionalidade longitudinal configura-se como a efetivação do processo sintético da recordação, possibilitando um processo de síntese sem um núcleo a priori. Husserl (1994, p. 105) ainda afirma que "há um fluxo de consciência uno e único, no qual se constitui a unidade temporal imanente do som e, ao mesmo tempo, a própria unidade do fluxo da consciência”. Dessa maneira, as duas intencionalidades se estabelecem em uma relação de retenção e protenção, as quais "devem unir o passado e o futuro no 'agora', dando-lhe o caráter de 'presente vivo e fluente'. O presente, enquanto recebido pelo passado, é retenção; enquanto recebe o futuro, é protenção" (FRAGATA, 1959, p. 125). Por conseguinte, a constituição será obra do fluxo absoluto da consciência (HUSSERL, 1994). Em um apêndice das Lições, cuja data de elaboração em correspondência com os manuscritos de Husserl é desconhecida, o autor afirma que a consciência tem uma essência própria que é "ser não apenas em geral, mas ser antes uma unidade de vivência e ser dada na consciência interna” (HUSSERL, 1994, p. 141). Com efeito, a teoria da consciência, apresentada nas Lições, expõe uma perspectiva da consciência de certo modo contrária à que aparece nas Ideias I, proporcionando o substrato teórico suficiente para Sartre se contrapor a Husserl. 
Ademais, ressalta-se que mesmo Husserl tendo feito a distinção entre Intencionalidade transversal e Intencionalidade longitudinal, as duas são inseparáveis, de modo que ambas estão "entrelaçadas uma na outra, exigindo-se uma à outra como dois lados de uma mesma coisa" (HUSSERL, 1994, p. 107). Deste modo, haja vista que o fluxo de uma consciência una constitui a síntese da multiplicidade fenomênica por meio de uma percepção de algo, faz-se necessária a distinção de Husserl entre percepção interna e externa, tema já abordado em Investigações Lógicas. Porém, na obra de 1900, a distinção se dá entre percepção interna e percepção adequada (HUSSERL, 2015). Dessa feita, o apêndice XI, com datação de 1907, o fenomenólogo alemão recusa a locução "percepção interna”, considerando como terminologia mais exata as expressões "percepção adequada" e "percepção externa" como inadequada. Em linhas gerais, nas Lições, a percepção adequada diz respeito à "consciência interna do objeto imanente duradouro, a qual está disponível mesmo que não atentemos nela, a saber, como consciência temporal”, ao passo que a percepção inadequada remete a três definições: (i) "A aparição externa"; (ii) "A consciência constituinte, em que se constitui a aparição externa como algo imanente"; e (iii) "A atenção, que pode ser quer um atentar na aparição e nos seus componentes quer um atentar no que aparece. Apenas o último está em questão quando se fala de percepção externa” (HUSSERL, 1994, p. 118). Portanto, a partir desses pontos, aliados à consciência interna, realiza-se a síntese do objeto no tempo. Assim, é possível realizar, a partir da fenomenologia husserliana, a rejeição do "Eu" puro, de maneira que Sartre começa a lançar as bases para uma possível refutação do idealismo, a qual só será concretizada em O Ser e o Nada. 


\section{A INTENCIONALIDADE EM A TRANSCENDENNCIA DO EGO E SUAS CON- SEQUÊNCIAS}

Devido ao processo crítico que caracteriza a primeira parte d'A Transcendência do Ego, constata-se que a consciência é liberada por meio da Intencionalidade, tornando-se um "campo transcendental impessoal" (SARTRE, 1966, p. 19), pois nem o "Eu” nem qualquer conteúdo psíquico poderá ser assimilado pela imanência da consciência. É importante ressaltar que, em Sartre (1966, p. 21), a consciência é definida pela Intencionalidade, de maneira que analisar suas características é analisar a natureza da própria consciência. Deste modo, torna-se plausível a rígida crítica de Sartre a Husserl. Concordar com a Intencionalidade de Husserl é ser conivente com toda uma estrutura idealista de pensamento. Por isso, Sartre leva às últimas consequências a crítica à consciência intencional interpretada por Husserl. Dessa maneira, a discussão de interpretação e aplicação do conceito de Intencionalidade está diretamente ligada ao projeto sartriano de apresentar uma alternativa ao realismo e ao idealismo absolutos.

Com efeito, a consciência intencional e seu correlato não são caracterizados por uma relação de identidade, pois o "algo" com o qual a consciência se relaciona é sempre diferente da consciência. Deste modo, segundo Mouille (2000, p. 14): “A consciência não abriga nenhum polo identitário. A psicologia muda de estatuto: fundada pela fenomenologia transcendental, ela não é mais o estudo introspectivo da alma ou o exame dos fatos psíquicos, mas o de uma lógica reflexiva”. ${ }^{14}$ Mouille apresenta-nos uma dupla referência estrutural da constituição de toda consciência intencional. Para

14. "La conscience n'abrite aucun pôle identitaire. La psychologie change de statut : fondée par la phénoménologie transcendantale, elle n'est plus l'étude introspective de l'âme ou l'examen des faits psychiques mais celle d'une logique réflexive." 
ele, além de a consciência ser consciência de alguma coisa, toda consciência de alguma coisa é consciente (MOUILLE, 2000). Tal constatação se dá pelo fato de que a consciência não existe sem estabelecer uma relação com alguma coisa. Posto isso, além da expulsão de todos os conteúdos da consciência, a Intencionalidade possibilita sua autounificação. A respeito disso, o autor sintetiza:

A consciência se unifica, se totaliza e individualiza a si mesma. De um lado, ela transcende em direção a um objeto que lhe fornece seu ponto de apoio transcendente, em torno do qual a unidade concreta e real das consciências se forma. De outro, como consciência temporalizante, ela própria efetua a autounificação dos objetivos constitutiva de toda experiência. ${ }^{15}$ (MOUILLE, 2000, p. 32-33)

Ressalta-se que, em A Transcendência do Ego, a fenomenologia de Sartre ainda não apresenta um total rompimento com a fenomenologia de Husserl, tal como ocorrerá em O Ser e o Nada. Segundo Flajoliet (2008, p. 816), Sartre mostra que uma "vontade de colocar seus passos nos de Husserl conduz sua fenomenologia em direção a um idealismo transcendental"16. Contudo, como os ditames da filosofia de Sartre ainda não estão bem constituídos, pode-se interpretar as teses d'A Transcendência do Ego como um tipo de materialismo bem específico (FLAJOLIET, 2008). Os argumentos de Sartre ainda não se encontram bem desenvolvidos, de maneira que o caráter ambíguo do Ego e das características da consciência está presente em toda sua obra de juventude. Com efeito, essa liberação do campo transcendental da consciência

15. "La conscience s'unifie, se totalise et s'individue d'elle-même. D'une part, elle se transcende vers un objet qui lui fournit son point d'appui transcendant, autour duquel l'unité concrète et réelle des consciences se forme. D'autre part, en tant que conscience temporalisante, elle effectue d'elle-même l'auto-unification des visées constitutive de toute expérience."

16. "volonté de mettre ses pas dans ceux de Husserl entraîne sa phénoménologie vers un idéalisme transcendantal." 
torna possível certa superação do solipsismo em A Transcendência do Ego, pois "não há nenhuma interioridade que seja como uma ilha no seio do mundo, o campo transcendental não subjetivado com o qual se identifica a imanência pura sendo radicalmente privado de conteúdo" ${ }_{17}$ (MOUILLE, 2000, p. 14). Contudo, enfatiza-se que a solução do problema do solipsismo desenvolvida em A Transcendência do Ego não é mantida em O Ser e o Nada, pois, na visão de Sartre, a refutação de 1934 é insatisfatória. No ensaio de ontologia fenomenológica, de 1943, a superação do solipsismo estará relacionada com o fato de a consciência se encontrar afetada "em seu próprio ser" pelo ser de outras consciências ${ }^{18}$ (MOUILLE, 2000, p. 14). Sartre, na conclusão d'A Transcendência do Ego, afirma que o "Mundo" e o "Eu” (Moi) não criam um ao outro. Deste modo, por meio da Intencionalidade, que libera a consciência dos seus conteúdos, Sartre inicia um processo de superação do problema do solipsismo, presente nas filosofias idealistas e realistas. Ademais, a consciência, ao se tornar absoluta, "é purificada do Eu [Je], não há mais nada [rien] de um sujeito, não é tampouco uma coleção de representações: ela é, simplesmente, uma condição primeira e uma fonte absoluta de existência”" ${ }^{19}$ (SARTRE, 1966, p. 87, grifo do autor).

Última consequência da noção de Intencionalidade abordada no presente trabalho é uma possível refutação do idealismo. De certo modo, a superação do solipsismo está relacionada com a refutação do idealismo, pois criticar as doutrinas transcendentais ${ }^{20}$ implica propor uma terceira

17. "il n'y a aucune intériorité qui soit comme un îlot au sein du monde, le champ transcendantal a-subjectif avec lequel s’identifie l'immanence pure étant radicalement dénué de contenu.”

18. Não é objetivo deste trabalho discutir os pormenores das refutações ao solipsismo da Transcendência do Ego e de O Ser e o Nada. Pois, para tamanho empreendimento, seria necessário expor a evolução conceitual da noção de consciência em Sartre. Para melhor compreensão do problema do solipsismo em $O$ Ser e o Nada, conferir a terceira parte da respectiva obra, a saber, O Para-Outro (SARTRE, 2015, p. 287-512).

19. "est purifiée du Je, n’a plus rien d’un sujet, ce n'est pas non plus une collection de représentations: elle est tout simplement une condition première et une source absolue d'existence."

20. "Por exemplo, a filosofia de Kant, Husserl e no caso específico d'A Transcendência do Ego, o neokantismo de Brunschvicg (SARTRE, 1966). 
via para extinguir a possibilidade de a consciência do sujeito deduzir os predicados da realidade exterior. Sartre, na conclusão d'A Transcendência do Ego, ressalta o caráter da fenomenologia se debruçar na realidade, pois ela se depara com "resistências exteriores, em que o sofrimento, a fome, a guerra se diluem no lento processo de unificação das ideias, [de modo que] nada é mais injusto do que chamar os fenomenólogos de idealistas" ${ }_{21}$ (SARTRE, 1966, p. 86). Desse modo, segundo Sartre, a acusação de idealismo é injusta porque o Eu (Moi) é um existente no mundo e sua existência possui as mesmas características que o mundo, do qual ele é contemporâneo. Então, a crítica de que a fenomenologia de Sartre é um idealismo, em A Transcendência do Ego, não se sustenta (SARTRE, 1966). Contudo, isso não exclui o fato de que há muitas influências idealistas impregnadas no pensamento do jovem Sartre, de modo que uma refutação mais consistente do idealismo da tradição filosófica só ocorrerá em O Ser e o Nada. Porém, as bases fenomenológicas de todo desenvolvimento já estão presentes em $A$ Transcendência do Ego (CONTAT; RYBALKA, 1970, p. 56).

\section{CONCLUSÃO}

Em conclusão, a partir da noção de Intencionalidade, apresentada por Sartre em seu breve ensaio sobre Husserl e aplicado em A Transcendência do Ego, constata-se que Sartre pôde romper com a "filosofia digestiva" do idealismo francês e com as doutrinas transcendentais que postulam um núcleo unificador formal na consciência, as quais abrem precedentes para a propagação do mito da "vida interior". Contudo, com a interpretação original de Sartre a respeito da Intencionalidade, a consciência expulsa todos os conteúdos imanentes de seu âmbito de realidade, reapreendendo-os no

21. "résistances extérieures, où la souffrance, la faim, la guerre se diluent dans un lent processus d'unification des idées, rien n'est plus injuste que d'appeler les phénoménologues des idéalistes." 
mundo.

Com efeito, Sartre, em A Transcendência do Ego, utiliza-se da Intencionalidade para definir a consciência e assim desenvolver a tese de que o Ego é um objeto transcendente como os demais objetos mundanos. Para isso, realiza um processo crítico das doutrinas transcendentais (Kant e Husserl), as quais foram priorizadas neste artigo, particularmente a fenomenologia de Husserl. Dessa maneira, Sartre estabelece uma crítica profunda da fenomenologia de Husserl desde sua psicologia descritiva de Investigações Lógicas até sua fenomenologia transcendental de Ideias I. O autor detecta uma contradição na fenomenologia husserliana, sobretudo após os argumentos de Lições. Segundo Sartre, Husserl não precisava estabelecer um "Eu" como polo unificador das vivências e ponto de partida da Intencionalidade, em Ideias I, uma vez que, nas Lições, Husserl concebeu que a própria consciência, por um jogo de intencionalidades, realiza a síntese das vivências sem a necessidade de um "Eu" puro. Nesse aspecto, surge a grande diferença entre a Intencionalidade de Husserl e a de Sartre, pois, em Husserl, a Intencionalidade tem sua origem no "Eu" puro, de modo que todo o "conhecer" se submete a uma estrutura idealista e solipsista. No entanto, em Sartre, em concordância com a postura husserliana das Lições, o próprio fluxo da consciência intencional realiza a síntese das vivências. A respeito disso, Sartre afirma: "[é] a consciência que se unifica a si própria e concretamente por um jogo de intencionalidades 'transversais' que são retenções concretas e reais das consciências passadas" ${ }_{22}$ (SARTRE, 1966, p. 22).

Por último, por meio da Intencionalidade, Sartre consegue liberar o campo transcendental da consciência, tornando-a vazia de conteúdo. Dessa maneira, pode-se constatar um grande passo para as investigações posteriores de Sartre a respeito das relações da consciência com o mundo. les' qui sont des rétentions concrètes et réelles des consciences passées." 
Com efeito, ressaltaram-se três consequências do estatuto da intencionalidade n'A Transcendência do Ego, a saber: (i) a liberação do campo transcendental, que retira da consciência a primazia idealista do sujeito sobre a realidade, pois o "Eu" de caráter transcendental é expulso da consciência; (ii) Sartre, ao postular que o Ego é transcendente, promove um grande avanço para uma possível superação do solipsismo, a qual só será concretizada definitivamente em O Ser e o Nada, mas que, em A Transcendência do Ego, já começa a ser delineada, pois o "Eu" perde o seu estatuto de "criador do universo" e se lança para a exterioridade e para o embate intersubjetivo; (iii) a possível refutação do idealismo consiste em compreender que o "Eu" e o mundo não criam um ao outro, de modo que a investigação filosófica/ fenomenológica procura expor as estruturas da relação entre a consciência e seu correlato. Dessa maneira, o mundo não é deduzido da consciência e a consciência não é deduzida do mundo. Por essas razões, buscou-se discorrer, neste artigo, acerca de algumas considerações sobre o estatuto da Intencionalidade na obra A Transcendência do Ego, de Jean-Paul Sartre. 


\section{REFERÊNCIAS}

ALVES, P. M. S. Irrefletido e reflexão: observações sobre uma tese de Sartre. In: SARTRE, J.-P. A Transcendência do ego. Lisboa: Colibri, 1994.

BARATA, A. Metáforas da consciência: da ontologia especular de Jean-Paul Sartre a uma metafísica da ressonância. Porto: Campos das Letras, 2000.

BEAUVOIR, S. A força da idade. Tradução de Sérgio Milliet. 5. ed. Rio de Janeiro: Nova Fronteira, 2018.

CONTAT, M.; RYBALKA, M. Les Écrits de Sartre: chronologie bibliographie commentée. Paris: Gallimard, 1970.

COHEN-SOLAL, A. Sartre: 1905-1980. Tradução de Milton Persson. São Paulo: L\&PM, 1986.

COOREBYTER, V. Sartre face à la phénoménologie: autour de "L’intentionnalité" et de "La transcendance de l'Ego". Bruxelas: Ousia, 2000.

DESANTI, J.-T. Sartre et Husserl ou les trois culs-de-sac de la phénoménologie transcendantale. Le Temps Modernes, Paris, v. 4-5-6, n. 632-633634, p. 571-584, 2005.

FLAJOLIET, A. La première philosophie de Sartre. Paris: Champion, 2008.

FRAGATA, J. A fenomenologia de Husserl como fundamento da filosofia. Braga: Livraria Cruz, 1959.

1962.

Problemas da Fenomenologia de Husserl. Braga: Livraria Cruz,

HUSSERL, E. A ideia da fenomenologia. Tradução de Artur Morão. Lisboa: Edições 70, 2000.

Investigações lógicas: investigações para fenomenologia e a teoria do conhecimento. Tradução de Pedro M. S. Alves e Carlos Aurélio Morujão. Rio de Janeiro: Forense Universitária, 2015.

Investigações lógicas: prolegômenos à lógica pura. Tradução de Diogo Ferrer. Rio de Janeiro: Forense Universitária, 2014.

Ideen zu einer reinen phänomenologie und phänomenologischen philosophie. Leiden: Martinus Nijhoff, 1950.

Ideias para uma fenomenologia pura e para uma filosofia fenomenológica. Tradução de Márcio Suzuki. 6. ed. Aparecida: Ideias \& Le- 
tras, 2006.

Lições para uma fenomenologia da consciência interna do tempo. Lisboa: Imprensa Nacional: Casa da Moeda, 1994.

MÉSZÁROS, I. A obra de Sartre: busca da liberdade e desafio da história. Tradução de Rogério Bettoni. São Paulo: Boitempo, 2012.

MOUILLE, J.-M. Sartre: conscience, ego et psychè. Paris: Presses Universitaires de France, 2000.

MOUTINHO, L. D. Sartre: psicologia e fenomenologia. São Paulo: Brasiliense, 1995.

SARTRE, J.-P. A imaginação. Tradução de Luiz Roberto Salinas Fortes. São Paulo: Abril, 1973.

Diários de uma guerra estranha. Tradução de Aulyde Soares Rodrigues. Rio de Janeiro: Nova Fronteira, 1983.

La transcendance de l'Ego: esquisse d'une description phénoménologique. Paris: J. Vrin, 1966.

O imaginário: psicologia fenomenológica da imaginação.

Tradução de Duda Machado. São Paulo: Ática, 1996.

O ser e o nada: ensaio de ontologia fenomenológica. Tradução de Paulo Perdigão. 24. ed. Petrópolis: Vozes, 2015.

Situations I. Paris: Gallimard, 1947.

SILVA, F. L. Ética e Literatura em Sartre: ensaios introdutórios. São Paulo: Editora Unesp, 2014. 